\title{
BMJ Open Incidence, types and acceptability of pharmaceutical interventions about drug related problems in a general hospital: an open prospective cohort
}

\author{
Valdjane Saldanha (D) , ${ }^{1}$ Rand Randall Martins, ${ }^{2}$ Sara lasmin Vieira Cunha Lima, ${ }^{1}$ \\ Ivonete Batista de Araujo, ${ }^{2}$ Antonio Gouveia Oliveira ${ }^{2}$
}

To cite: Saldanha V, Randall Martins R, Lima SIVC, et al. Incidence, types and acceptability of pharmaceutical interventions about drug related problems in a general hospital: an open prospective cohort. BMJ Open 2020;10:e035848. doi:10.1136/ bmjopen-2019-035848

- Prepublication history for this paper is available online. To view these files, please visit the journal online (http://dx.doi. org/10.1136/bmjopen-2019035848).

Received 18 November 2019 Revised 10 February 2020 Accepted 20 March 2020

Check for updates

(C) Author(s) (or their employer(s)) 2020. Re-use permitted under CC BY-NC. No commercial re-use. See rights and permissions. Published by BMJ.

${ }^{1}$ Department of Pharmacy, Postgraduate Program in Pharmaceutical Sciences, Centro de Ciências da Saúde, Universidade Federal do Rio Grande do Norte, Natal, Rio Grande do Norte, Brazil ${ }^{2}$ Department of Pharmacy, Centro de Ciências da Saúde, Universidade Federal do Rio Grande do Norte, Natal, Rio Grande do Norte, Brazil

Correspondence to Dr Valdjane Saldanha; valdjanesaldanha@yahoo. com.br

\section{ABSTRACT}

Objectives To evaluate the incidence and types of drugrelated problems (DRP) in a general teaching hospital and to evaluate the acceptability of pharmaceutical interventions by the medical team.

Design Prospective cohort study during 2 years. Setting Conducted in a Brazilian University Hospital. Participants The patient cohort consisted of 9303 patients with a total of 12286 hospitalisation episodes. Primary outcome measures DRP detected by pharmacists' review of $100 \%$ medication orders using Pharmaceutical Care Network Europe 6.2 classification. Results Patients with a mean age of $52.6 \pm 17.7$ years and $50.9 \%$ females. A total of 3373 DRP in 1903 hospital episodes were identified, corresponding to a cumulative incidence of $15.5 \%$. 'Treatment ineffectiveness' (11.5\%) and 'Treatment costs' $(5.90 \%)$ were the most common DRP and 'Drug use process' (18.4\%) and 'Treatment duration' $(31.0 \%)$ the main causes of DRP. The medicines involved most often involved in DRP were anti-infectives $(36.0 \%)$, mainly cephalosporins (20.2\%), antiulcer $(38.6 \%)$, analgesics/antipyretics (61.2\%), propulsives (51.2\%), opioids (38.5\%) and antiemetics (57.4\%). From 1939 pharmaceutical interventions, at least, $21.4 \%$ were not approved by the medical team.

Conclusion DRP detected by $100 \%$ medication order review by hospital pharmacists occur in a significant proportion of hospital episodes, the most frequent being related to treatment effectiveness and treatment costs. The medications mostly involved were cephalosporins, penicillins, antidyspeptics, analgesics, antipyretics, opioids and antiemetics. Pharmaceutical interventions had low acceptability by the medical staff.

\section{INTRODUCTION}

Drug-related problems (DRP) are defined as events or circumstances involving pharmacotherapy that actually or potentially interfere with desired health outcomes. ${ }^{1}$ DRP are classified as manifested or potential. They are considered adverse events and occur in patients at all levels of healthcare, whether home care, ${ }^{2}$ institutional long term care, ${ }^{3}$ community pharmacy ${ }^{4}$ or hospital. ${ }^{5}$ In the
Strengths and limitations of this study

- Very few studies have analysed the incidence and types of drug-related problems (DRP) in patients hospitalised in general medical and surgical wards.

- A strength of this study is the prospective design based on open cohort of all adult patients hospitalised in a general hospital with DRP identified by review of $100 \%$ medication orders by clinical pharmacists.

- Another strength is the extended period of observation that allows the exclusion of seasonality bias due to changing disease incidences throughout the year.

- The main limitation was not to be able to include adverse reactions, dispensing errors and drugadministration errors, which are also considered DRP.

- Another limitation to the generalisation of the results was the conduct of the study in a single hospital.

hospital setting, incidence rates of DRP have been reported for specific patient populations, with high incidence rates in children ${ }^{6}$ and the elderly, ${ }^{7}$ as well as in certain clinical specialties such as cardiology, ${ }^{8}$ neurology ${ }^{9}$ and surgery. ${ }^{7}$

This high incidence of DRP negatively affects the quality of life of the patient and increases the economic and social burden of illnesses. ${ }^{5}$ Many of the admissions to emergency departments, ${ }^{10}{ }^{11}$ many causes of extended hospital stays ${ }^{12}$ or of patient re-admissions ${ }^{13}$ and even of deaths, are due to a DRP. It has been reported that these negative outcomes are proportional to the complexity of the drug use process, ${ }^{14}$ with some of the described risk factors being polypharmacy, hepatopathies, nephropathies and the use of high-risk medicines. ${ }^{15}$

The detection and classification of potential DRP by pharmacy services is the first step to prevent harm to the patient, ${ }^{16}$ contributing to a reduction in medication errors, 
adverse reactions and length of stay. ${ }^{17}$ Several systems have been proposed for the classification of DRP, with the Pharmaceutical Care Network Europe (PCNE) being one of the most commonly used classification systems in hospital practice. ${ }^{18}$ Several DRP detection strategies have been developed, including pharmacist review of medication orders (MO), the use of computerised physician order entry (CPOE) systems couple with clinical decision support programs ${ }^{19-21}$ that allow the clinical pharmacist to have an active participation within the healthcare team. ${ }^{582-24}$ However, despite the clinical and economic relevance of DRP, very few studies have investigated the incidence, types and causes of DRP in patients hospitalised in general medical and surgical wards.

Therefore, the objective of the present study was to describe DRP detected by pharmacist review of all MOs issued to all patients hospitalised in medical and surgical wards throughout their stay in a general teaching hospital to evaluate the frequency, type and cause of DRP detected by this method, and the acceptability of pharmaceutical interventions by the medical staff.

\section{METHODS}

This prospective cohort study was conducted at the University Hospital Onofre Lopes, a public hospital in Natal, Brazil, a medium-sized tertiary care hospital, during two uninterrupted years (May 2016 to April 2018). The hospital has 247 beds and approximately 8000 admissions per year. It is organised in the departments of nephrology, urology, cardiology, surgery (general, neurological, cardiovascular and oncological), endocrinology, rheumatology, neurology, gastroenterology and psychiatry.

All patients over 18-years-old who were hospitalised during the study period for more than 24 hours and for whom at least one drug was prescribed were included in the study. Patients hospitalised only for diagnostic purposes and patients admitted to an intensive care unit were excluded. Solutions of electrolytes, parenteral nutrition solutions, whole blood and blood products, oxygen therapy and diagnostic agents were not considered in the review of $\mathrm{MO}$ because they did not have a recommended dose. MO containing anticancer drugs were not included in the research because in our institution they are not entered into the CPOE and are evaluated by clinical pharmacists specialised in oncology.

The MO of each specialty were entered into a CPOE. The CPOE in use at our institution makes clinical data and the hospital formulary adopted at the institution available to the prescriber for selection at the time of preparation of the MO, but does not have a system for issuing electronic alerts to identify DRP. MO are sent electronically to the hospital pharmacy service for the review process by the pharmacist, a step that precedes the dispensing of the medicines.

MO review was performed by a team of hospital pharmacists composed of 21 pharmacists divided into smaller groups of three elements. These groups took turns reviewing all individual MO that were sent to the hospital pharmacy service 24 hours a day, 7 days a week, for 2 consecutive years.

For this study, DRP were defined, according to the PCNE, version 6.2 (PCNE 6.2), as any event or circumstance involving drug therapy that would, actually or potentially, interfere with the desired health outcomes. ${ }^{1}$ Pharmacist review of MO was carried out with the objective of detecting potential DRP by evaluating a predefined and standardised set of identifiable items. These included medication name, availability, dose, route of administration, pharmaceutical form, frequency of use, dilution, infusion time, duration of treatment, therapeutic duplicity, cost-effectiveness, legal aspects of the prescription, use of non-standard abbreviations in the hospital and absence of information relevant to the safe use of the drug. This type of review, in which the pharmacists looked for specific items in the MO, we call Simplified Medication Order Review (SMOR).

DRP were classified according to PCNE 6.2. The PCNE system assigns to each DRP four possible domains with respective subclassifications: (1) problem (treatment ineffectiveness, adverse reactions, treatment costs, others); (2) cause of the problem (drug selection, drug form, dose selection, treatment duration, drug use process, logistics, patient, other); (3) intervention required to solve or avoid the problem (no intervention, intervention at the prescriber level, at the patient/carer level, at drug level, others); (4) outcome of the interventions (unknown, solved, partially solved, not solved).

Based on the identification of DRP, the hospital pharmacists team issued interventions for each case using Micromedex (Truven Health Analytics, Lansing, MI, USA), Uptodate (UpToDate Inc., Waltham, MA, USA) and recommendations of the manufacturer of each drug when analysing the possibility of occurrence of a DRP due to physical-chemical and/or microbiological stability characteristics. Information on the DRP was reviewed by an experienced clinical pharmacist, and in divergent cases a third pharmacist was consulted.

All DRP were recorded manually in a log book, along with the patient identification and detailed description of the DRP, and a pharmaceutical intervention was issued, containing a proposal to change the $\mathrm{MO}$ in order to prevent the occurrence of DRP. The intervention proposal was written on a Pharmaceutical Intervention (PI) form and sent by messenger to the patient ward. There, the PI form was attached to the patient chart to be viewed before the next prescription.

Our study did not evaluate the outcome of DRP, considering that the problem detected by the SMOR is a potential problem, not a manifested DRP. We did, however, assess the acceptability by the medical team of the pharmaceutical interventions issued during the SMOR: changes in $\mathrm{MO}$ after 72 hours of follow-up, consistent with what was proposed by the pharmacist in the intervention, were considered as accepted by the notified prescriber. 
All patients were observed throughout the entire hospital stay up to hospital discharge or death. All medicines prescribed to each patient were recorded and classified according to the Anatomical Therapeutic Chemical (ATC) Classification System.

\section{Statistical analysis}

To avoid bias due to seasonality, it was determined that inclusion of patients would be carried out without interruption for 2 years. During this period it was estimated that there would be about 16000 hospitalisation episodes, corresponding to approximately $100000 \mathrm{MO}$ and 1600000 prescribed items evaluated. This sample size ensured a maximum error of estimates of 0.8 percentage points with $95 \%$ confidence.

Interval variables were described by mean $\pm \mathrm{SD}$ and binary variables by absolute and relative frequency. Statistical analysis was performed using Stata V.12.

\section{Patient and public involvement}

No patients were involved in setting the research question or the outcome measures, nor were they involved in developing plans for or implementation of the study. No patients were asked to advise on interpretation or writing up of results.

\section{RESULTS}

The study was conducted between May 2016 and April 2018. During this period, there were 15005 hospital admissions and about 2 million doses of medication were dispensed. Our sample consisted of 12286 hospitalisation episodes in 9303 distinct patients with mean age at first hospitalisation of $52.6 \pm 17.7$ years, of which 6250 were women (50.9\%). The hospital pharmacy reviewed 117022 MO in these patients. The hospital offers clinical and surgical hospitalisation in different medical specialties, with cardiology (12.6\%) and general surgery $(8.01 \%)$ being the most common. The median length of stay was 2.93 days (range $1-474$ days) (table 1 ).

In 1903 hospital episodes, one or more DRP was detected, corresponding to a cumulative incidence of DRP of $15.5 \%$. A total of 3373 DRP were identified, corresponding to an incidence density of $1.71 \%$ patient-days and representing a mean of $0.27 \pm 0.81 \mathrm{DRP}$ per patient. According to PCNE 6.2, DRP classified as 'P1.Treatment

\begin{tabular}{|c|c|c|}
\hline \multirow{2}{*}{$\begin{array}{l}\text { Characteristics } \\
\text { Age in years }(m, S D)\end{array}$} & \multicolumn{2}{|c|}{ Descriptive statistics } \\
\hline & 52.6 & 17.7 \\
\hline Female $(n, \%)$ & 6250 & 50.9 \\
\hline Length of stay (median, range) & 2.93 & $1-474$ \\
\hline In-hospital mortality (n, \%) & 666 & 5.42 \\
\hline
\end{tabular}

$\%$, relative frequency; $m$, mean; $n$, absolute frequency; SD, standard deviation.
Table 2 Cumulative incidences of drug-related problems (DRP) according to version 6.2 of the PCNE classification.

\begin{tabular}{lll}
\hline & \multicolumn{2}{c}{$\begin{array}{c}\text { Cumulative } \\
\text { incidence }\end{array}$} \\
\cline { 2 - 3 } DRP type & $\mathbf{n}$ & $\%$ \\
\hline $\begin{array}{l}\text { P1-Treatment effectiveness } \\
\text { P1.1-No effect of drug treatment/ } \\
\text { therapy failure }\end{array}$ & 257 & 2.09 \\
$\begin{array}{l}\text { P1.2-Effect of drug treatment not } \\
\text { optimal }\end{array}$ & 1132 & 9.21 \\
$\begin{array}{l}\text { P1.3-Wrong effect of drug } \\
\text { treatment }\end{array}$ & 24 & 0.19 \\
$\begin{array}{l}\text { P3-Treatment costs } \\
\begin{array}{l}\text { P3.1-Drug treatment more costly } \\
\text { than necessary }\end{array}\end{array}$ & 725 & \\
\hline $\begin{array}{l}\text { P4-Others } \\
\text { P.4.2-Unclear problem/complaint }\end{array}$ & 301 & \\
\hline
\end{tabular}

PCNE, Pharmaceutical Care Network Europe.

Effectiveness', which includes DRP for 'no effect of drug treatment/therapy failure 'effect of drug treatment not optimal', 'wrong effect of drug treatment' and 'untreated indication' was observed in $1413(11.5 \%)$ patients, the most frequent being 'effect of drug treatment not optimal' (9.21\% of patients) (table 2). DRP classified as 'P3.Treatment Costs', which are those related to the use of drugs more expensive than necessary to treat a certain disease, were identified in $725(5.90 \%)$ patients. DRP classified as 'P4.Others' occurred in 301 patients (2.45\%) and refers to those in which the patient is not satisfied with the therapeutic and/or economic outcome, or those whose classification system was not able to include, such as non-compliance with treatment, use of commercial name, incomplete prescription, use of non-standard abbreviations, difficulty in interpreting $\mathrm{MO}$ and type of pharmaceutical formulation. The SMOR process could not identify DRP of the 'P2.Adverse reactions' type, which encompass drug (allergic/non-allergic) adverse events and toxic adverse drug events.

Concerning the causes of DRP (table 3), the P1 type was mainly caused by inadequacies in the 'C5. Drug use process', which include inadequate timing of administration, inadequate or unsafe site or route of administration, insufficient dilution volume and inadequate diluent. These causes represented $18.4 \%$ of the causes of DRP, with an incidence density of $0.16 \%$ patient-days. DRP's caused by 'C6. Logistics', which include drug unavailability, prescription error and dispensing error, represented $17.9 \%$ of the DRP, with an incidence density of $0.31 \%$ patient-days. 'C3. Dose selection' represented $16.1 \%$ of the DRP, with an incidence of $0.28 \%$ patient-days. 'C4. Treatment duration' was the most frequent DRP cause (31.0\% of DRP and incidence density of $0.53 \%$ patientdays), associated only with the occurrence of DRPs classified as 'P3. Treatment costs'. The only cause of the DRP 
classified as 'P4. Others' was 'C6. Logistics $(10.9 \%$ and $0.19 \%$ patient-days), which included how the drug would be used (infusion time, frequency, the route by which it will be administered), unavailability of the prescribed drug or prescription error. ${ }^{23}$ The cumulative incidence of each DRP cause is also shown in table 3.

Antimicrobials were implicated in approximately $36 \%$ of the DRP, mainly cephalosporins (J01D, 20.2\%) and penicillins (J01C, 6.08\%). The ATC therapeutic classes more often involved in DRP and the frequency distribution of the respective causes are shown in table 4. Among anti-infectives for systemic use, 'C4. Treatment duration' was the main cause of DRP, representing from $61 \%$ to $68 \%$ of all DRP causes among the different therapeutic classes of anti infectives. 'C6. Logistics' was another common cause of DRP in some ATC therapeutic classes, such as antipsychotic drugs (A02B, 38.6\% of all causes), analgesics and antipyretics (N02B, $61.2 \%$ of all causes) and propulsive drugs (A03F, 51.2\% of all causes). The DRP observed with opioids (N02A) and antiemetics (A04A) were mainly caused by 'C5. Drug use process' (38.5\% and $57.4 \%$ of all causes, respectively).

From the 3373 pharmaceutical interventions performed, 1939 were followed up to assess their acceptability by the prescriber. From these, 1217 (36.10\%) were considered 'approved' because there was a change in the MO in the same sense as the proposed pharmaceutical intervention. In $722(21.4 \%)$ cases, the interventions were classified as 'not approved' by the prescriber, since they did not generate changes on the MO (table 5).

Some pharmaceutical interventions could not be evaluated regarding acceptability by the healthcare team because they would not dictate a change in the respective MO. These include cases where the patient was discharged or died before a MO could be changed, when the pharmaceutical intervention proposed a change in the technique of drug preparation, mentioned an issue related to the physical-chemical stability of the drug, or provided instructions on the correct administration of the drug. These situations accounted for $1433(42.5 \%)$ of cases and were classified as 'unknown'.

\section{DISCUSSION}

Our study assessed the incidence of DRP among adult patients hospitalised in medical and surgical wards of a general hospital using an open prospective cohort for a period of 2 years. The detection of DRP was done by the review by hospital pharmacists of all MO issued by a CPOE system without alerts, according to a checklist for reviewing MO, the DRP being classified according to the PCNE version 6.2.

In this study we estimated that with this centralised simplified method of MO review, DRP are detected

\begin{tabular}{|c|c|c|c|c|c|}
\hline \multirow[b]{2}{*}{ DRP type } & \multirow[b]{2}{*}{ DRP cause } & \multicolumn{2}{|c|}{ Frequency distribution } & \multicolumn{2}{|c|}{ Cumulative incidence } \\
\hline & & n & $\%$ & $\mathbf{n}$ & $\%$ \\
\hline \multirow{7}{*}{$\begin{array}{l}\text { P1-Treatment } \\
\text { effectiveness }\end{array}$} & C1.2-No indication for drug & 12 & 0.36 & 12 & 0.10 \\
\hline & $\begin{array}{l}\text { C1.4-Inappropriate duplication of therapeutic } \\
\text { group or active ingredient }\end{array}$ & 23 & 0.68 & 21 & 0.17 \\
\hline & C2.1-Inappropriate drug form (for this patient) & 7 & 0.21 & 6 & 0.05 \\
\hline & C3.2-Drug dose too high & 363 & 10.8 & 332 & 2.70 \\
\hline & C3.3-Dosage regimen not frequent enough & 180 & 5.34 & 167 & 1.36 \\
\hline & $\begin{array}{l}\text { C6.2-Prescribing error (necessary information } \\
\text { missing) }\end{array}$ & 335 & 9.93 & 234 & 1.90 \\
\hline & C8.1-Other cause; specify & 34 & 1.01 & 32 & 0.26 \\
\hline \multirow[t]{2}{*}{ P3-Treatment costs } & C1.7-More cost-effective drug available & 23 & 0.68 & 22 & 0.18 \\
\hline & C4.2-Duration of treatment too long & 1044 & 31.0 & 712 & 5.80 \\
\hline \multirow[t]{2}{*}{ P4-Others } & C5.7-Patient unable to use drug/form as directed & 1 & 0.03 & 1 & 0.01 \\
\hline & $\begin{array}{l}\text { C6.2-Prescribing error (necessary information } \\
\text { missing) }\end{array}$ & 368 & 10.9 & 301 & 2.45 \\
\hline Total & & 3373 & 100.0 & - & - \\
\hline
\end{tabular}

PCNE, Pharmaceutical Care Network Europe. 
Table 5 Acceptability of pharmaceutical interventions related to DRP

\begin{tabular}{lll}
\hline Acceptability & $\mathbf{n}$ & $\%$ \\
\hline $\begin{array}{l}\text { Intervention proposed, approved by } \\
\text { prescriber }\end{array}$ & 1217 & 36.1 \\
$\begin{array}{l}\text { Intervention proposed, not approved by } \\
\text { prescriber }\end{array}$ & 722 & 21.4 \\
$\begin{array}{l}\text { Intervention proposed, outcome } \\
\text { unknown }\end{array}$ & 1433 & 42.5 \\
\hline
\end{tabular}

DRP, drug-related problems.

in about one-sixth of all hospital episodes. The most common DRP are related to treatment effectiveness, due mainly to inadequacies in the drug use process and inadequate selection of drug dose, and to treatment costs caused mainly by prolonged treatments, involving mostly the therapeutic groups of analgesics/antipyretics and cephalosporins, respectively. It was also found that pharmaceutical interventions, proposed indirectly by means of written communiqués, had an acceptability rate by the medical staff that may be considered rather low.

The incidence of DRP observed in this study was different from the incidence reported in other studies conducted in hospitals of different types, ${ }^{25-27}$ which may be due, at least partially, to the diversity of the methodologies used to identify DRP, the classification of DRP, the communication with the medical team and the evaluation of the acceptability of pharmaceutical interventions. ${ }^{7} 2428{ }^{29}$ In addition, many published studies on the DRP incidence have been done in elderly hospitalised patients who, because of the polymedication often present in that population, are at increased risk of DRP.

The number of beds assigned to cardiology patients and the greater complexity of the pathology and associated comorbidities, ${ }^{30}$ especially heart failure and acute myocardial infarction, could in part explain those discrepancies. Drug-related problems predominate in clinical services, especially in cardiology, as compared with surgical services of general surgery. ${ }^{31}$

Very few studies have been published in which the analysis of all the $\mathrm{MO}$ of all the patients admitted to a general hospital was done. The large majority of published studies have described the frequency and type of DRP in patients of different medical specialties. Among studies conducted on a whole hospital, a prospective 18-month study between 2001 and 2003 in a university hospital examined 29016 computerised MO of 8152 patients by seven clinical pharmacists integrated in the medical team during ward rounds. The DRP identified were classified by two independent pharmacists using a checklist from the French Society of Clinical Pharmacy. In this study, the percentage of patients with one or more DRPs was significantly higher $(33.0 \%)$, with non-compliance with the guidelines or contraindication $(29.5 \%)$, inadequate administration (19.6\%), drug interaction $(16.7 \%)$ and over dosage (12.8\%) being the most frequent DRP types. 
Cardiovascular drugs were the most involved (22.2\%), followed by antimicrobials $(13.3 \%)$ and analgesics/antiinflammatory agents $(11.3 \%){ }^{25}$

Another prospective study, conducted in six departments of internal medicine and two departments of rheumatology in five hospitals in Norway between May and December 2002, evaluated the hospitalisations of 827 patients for the detection of DRP by clinical pharmacists through review of medical records and multidisciplinary meetings of therapy review, reported that $81 \%$ of patients had DRP, with an average of 2.1 clinically relevant DRP per patient. The most frequently reported DRP were dose-related problems $(35.1 \%$ of patients), followed by laboratory tests $(21.6 \%)$, nonoptimal medications $(21.4 \%)$ and need for additional medications $(19.7 \% \%)$, unnecessary drugs $(16.7 \%)$ and errors in the medical records $(16.3 \%)$. The drug classes that most often caused DRP were antithrombotic agents, non-steroidal anti-inflammatory drugs, opioids and ACE inhibitors. ${ }^{32}$

On the other hand, another study analysed all DRP identified in 44870 patients during 2014-2015 by reviewing the MO issued by a CPOE with alerts, by a team of 14 non-clinical pharmacists integrated in the ward rounds. The percentage of hospital episodes in which a DRP was observed was only $5.6 \%$, a value much lower than the one observed in our study. The main problems related to medication were prescription errors due to incorrect use of the computerised prescription system (18.1\%), drug interaction $(13.3 \%)$ and dose adjustment by renal and/ or hepatic function $(11.5 \%) .{ }^{14}$

According to several studies, the implementation of CPOE systems has been responsible for a considerable increase in safety related to the use of drugs. ${ }^{2033}$ However, these systems have also been associated with the appearance of DRP as a consequence of the lack of ability to use computational tools. ${ }^{34}{ }^{35}$ In fact, inadequate prescription from medication errors due to confusion with decimals, lack of information about the route of administration and infusion time, use of abbreviations non-standard in the institution and the use of molecular formulas contributed to the second highest cause of DRP detected in the present study, that of treatment ineffectiveness because of inadequate drug use process. On the other hand, one of the causes of the reduced incidence rate of DRP observed in our study may be related to the absence in our institution of a computerised system that, together with the CPOE system, would provide alerts and reports resulting from cross-referencing the patient's clinical information (diagnosis, comorbidities, lab results, serum concentration of medications) with the pharmacological information on the medications (dose requested and the patient's renal/hepatic function, weight, creatinine, adequate type and volume of the diluent, infusion time, frequency and route of administration). Without such an information system, it is difficult to identify several types of DRP, such as drug interactions, dose adjustments, overdoses, subdoses, among others.
In our study, anti-infectives, especially cephalosporins and penicillins, were the drugs most involved in DRP, mainly due to overuse. The high detection of this type of DRP was probably due to the direct involvement of pharmacists in the inventory control of this class of drugs, thus facilitating the identification of divergences between the expected treatment and what was actually being administered. Other groups also involved the antidyspeptics, analgesics and antipyretics that often presented the potential problem of treatment ineffectiveness caused by logistic problems of the prescription and dispensation process, especially prescription errors due to lack of relevant information such as volume and type of diluent, dose, infusion time, frequency and route of administration and non-availability of the substance. Another relevant group was opioids and antiemetics, more frequently due to failures in the use process, such as insufficient infusion time and dilution volume.

The simplified $100 \%$ review of MO by clinical pharmacists, prior to drug dispensing, is one of the main strategies for DRP prevention in patients followed at various levels of healthcare ${ }^{36-38}$ especially in a hospital environment, where the risk of DRP is related to several factors such as polypharmacy, comorbidities, use of high-risk medication, renal/hepatic insufficiency, clinical condition, prolonged hospitalisation, among others. ${ }^{23}{ }^{39}$ This is a very common reality in most health services. The implementation of pharmaceutical clinical services, whether in basic care or high complexity, not only reduces hospital costs ${ }^{40}$ but also minimises the occurrence of harm to the patient, of hospital admissions and readmissions and improves the quality of life of patients. ${ }^{45824374142}$

After MO review, all DRPs identified were the subject of a pharmaceutical intervention via a written statement addressed to the medical staff, regardless of DRP severity. However, only the results of the interventions aimed at the prescribers could be analysed, because of the ease of identification of changes in the MO, reflecting the actual approval of the intervention on the therapeutic plan of the patient. A relatively low rate of acceptability of the interventions was observed, possibly related to the fact that the clinical pharmacists who reviewed the MO were not integrated into the healthcare team, had no direct involvement with the patient care and did not participate in ward rounds. Other studies have reported significantly higher acceptability rates, and we believe that MO review during clinical meetings, with the participation of the clinical pharmacist within the healthcare team, predisposes to this and produces better outcomes in health. ${ }^{3}{ }^{43}$ This stresses the importance of DRP detection before dispensing the product to the patient, thereby promoting the minimisation of harms resulting from the medication process, ${ }^{828}$ since computer system alerts issued for $\mathrm{MO}$ revision do not seem sufficient to guarantee the effectiveness of the pharmaceutical interventions. ${ }^{44}$

A strength of the present study is the extended period of observation that allows the exclusion of the seasonality bias due to changing diseases characteristic throughout 
the year. A major feature of the study was to perform MO review in all patients admitted to all departments of a general hospital, thus providing a better insight into the size and extent of DRP in a health facility as a whole than is provided by a study in particular populations or in specialised departments. Another strong point of the methodology was to adopt internationally recognised standards to allow easier comparison of results among studies. In this sense, the PCNE classification system was chosen for its frequent application in studies that involve the identification and categorisation of DRP 22414546 and because it is a frequently used tool in hospital practice, ${ }^{18}$ although many other DRP classification systems have been proposed. ${ }^{47}$ Very few studies have been published in the literature in which pharmaceutical interventions were made through written communication with prescribers, acting as a warning system; other studies deal only with interventions made verbally during ward rounds.

The main limitation of this study was not to be able to include adverse reactions, dispensing errors and drug administration errors, which are also considered DRP. Other limitations to the generalisation of the results are the conduct of the study in a single hospital, although in many respects it shares a number of characteristics that are common to hospitals around the world. These include being a tertiary care medium sized general hospital within the public health system, of great importance to the region where it is located, with shortage of resources at the infrastructure, human and financial level, which correspond to the reality of the vast majority of public hospitals in the world.

Future research in this topic should seek to assess the frequency of manifested DRP, their outcomes, their impact on hospital costs, as well as the identification of risk factors for potential DRP and the development of risk stratification instruments for potential DRP and/or for required pharmaceutical interventions.

According to the findings of this study, a significant part of DRP can be prevented. Therapeutic ineffectiveness related to inadequacy in the use process is likely to be minimised through constant training of health teams, especially in relation to the rational use of antimicrobials, resulting in lower cost and less occurrence of bacterial resistances. Point-of-care access to updated and quality literature on drugs, in addition to regular updating of computerised warning and prescription assistance systems, would probably decrease DRP related to treatment effectiveness, the most often observed DRP in patient wards. It is also likely that the inclusion of clinical pharmacists as members of the healthcare would contribute largely to a significant decrease in the incidence of potential DRP.

In conclusion, DRP detected by $100 \%$ MO review by hospital pharmacists occur in a significant proportion of hospital episodes, the most frequent being related to treatment effectiveness and treatment costs, with the most common causes being inadequacy in the process of use and duration of treatment. The medications mostly involved were cephalosporins, penicillin, antidyspeptics, analgesics, antipyretics, opioids and antiemetics. The acceptance rate of pharmaceutical interventions through written communication to the medical staff was relatively low.

Acknowledgements The authors would like to thank the pharmacists of the University Hospital Onofre Lopes for the registration of the interventions and the students of the Pharmacy course Bruna Cordeiro Araújo, Gislayne Correia, José Marinaldo Filho, Maria Luiza Fernandes, Thaise Marijara Almeida, Tiago Viana, Mariana Fernandes Gomes, Luma Araújo Farias and Kaline dos Santos Lima for the data collection. We also thank Adriana Cristina Silva for informatics support.

Contributors All coauthors fulfill the criteria required for authorship. VC, AGO and IBA were responsible for study conception, AGO designed the study protocolol and VS contributed with data collection. AGO and RRM were resposible for data analysis and interpretation.VS drafted the manuscript. AGO and RRM revised the drafting for important intellectual content. IBA and SIVCL contributed with revies of the final draft. All authors contributed to the final approval of the version to be published and are in agreement to be accountable for all aspects of the work and in ensuring that questions related to the accuracy or integrity of any part of the work are appropriately investigated and resolved.

Funding This study was financed in part by Coordenação de Aperfeiçoamento de Pessoal de Nível Superior - Brasil (CAPES) - Finance Code 001.

Competing interests None declared.

Patient and public involvement Patients and/or the public were not involved in the design, or conduct, or reporting, or dissemination plans of this research.

Patient consent for publication Not required.

Ethics approval Study approval was obtained from the Hospital Research Ethics Committee with number 1439845 , which waived informed consent from patients because the research used only secondary data.

Provenance and peer review Not commissioned; externally peer reviewed.

Data availability statement Data are available upon reasonable request. Extra data are available by emailing valdjanesaldanha@yahoo.com.br.

Open access This is an open access article distributed in accordance with the Creative Commons Attribution Non Commercial (CC BY-NC 4.0) license, which permits others to distribute, remix, adapt, build upon this work non-commercially, and license their derivative works on different terms, provided the original work is properly cited, appropriate credit is given, any changes made indicated, and the use is non-commercial. See: http://creativecommons.org/licenses/by-nc/4.0/.

ORCID iD

Valdjane Saldanha http://orcid.org/0000-0001-5223-5061

\section{REFERENCES}

1 PCNE Pharmaceutical Care Network Europe. The definition of drugrelated problems. Available: https://www.pcne.org/upload/files/11_ PCNE classification V6-2.pdf. (2009) [Accessed 7 Feb 2020].

2 Meyer-Massetti C, Meier CR, Guglielmo BJ. The scope of drugrelated problems in the home care setting. Int $\mathrm{J}$ Clin Pharm 2018;40:325-34.

3 Silva C, Ramalho C, Luz I, et al. Drug-Related problems in institutionalized, polymedicated elderly patients: opportunities for pharmacist intervention. Int J Clin Pharm 2015;37:327-34.

4 Szilvay A, Somogyi O, Meskó A, et al. Qualitative and quantitative research of medication review and drug-related problems in Hungarian community pharmacies: a pilot study. BMC Health Serv Res 2019;19:282.

5 Tasaka Y, Tanaka A, Yasunaga D, et al. Potential drug-related problems detected by routine pharmaceutical interventions: safety and economic contributions made by hospital pharmacists in Japan. J Pharm Health Care Sci 2018;4:33.

6 Birarra MK, Heye TB, Shibeshi W. Assessment of drug-related problems in pediatric ward of Zewditu Memorial referral Hospital, Addis Ababa, Ethiopia. Int J Clin Pharm 2017;39:1039-46.

7 Qu C, Meng L, Wang N, et al. Identify and categorize drug-related problems in hospitalized surgical patients in China. Int J Clin Pharm 2019;41:13-17.

8 Urbina $\mathrm{O}$, Ferrández $\mathrm{O}$, Luque S, et al. Patient risk factors for developing a drug-related problem in a cardiology ward. Ther Clin Risk Manag 2015;11:9-15. 
9 Rodrigues JPV, Marques FA, Gonçalves AMRF, et al. Analysis of clinical pharmacist interventions in the neurology unit of a Brazilian tertiary teaching hospital. PLoS One 2019;14:e0210779.

10 Al Hamid A, Ghaleb M, Aljadhey H, et al. A systematic review of hospitalization resulting from medicine-related problems in adult patients. Br J Clin Pharmacol 2014;78:202-17.

11 Alghamdy MS, Randhawa MA, Al-Wahhas MH, et al. Admissions for drug-related problems at the emergency department of a university hospital in the Kingdom of Saudi Arabia. J Family Community Med 2015;22:44-8

12 Jourdan J-P, Muzard A, Goyer I, et al. Impact of pharmacist interventions on clinical outcome and cost avoidance in a university teaching hospital. Int J Clin Pharm 2018;40:1474-81.

13 Olson $\mathrm{CH}$, Dierich M, Adam T, et al. Optimization of decision support tool using medication regimens to assess rehospitalization risks. Appl Clin Inform 2014;5:773-88.

14 Ferrández O, Casañ B, Grau S, et al. [Analysis of drug-related problems in a tertiary university hospital in Barcelona (Spain)]. Gac Sanit 2019;33:361-8.

15 Kaufmann CP, Stämpfli D, Hersberger KE, et al. Determination of risk factors for drug-related problems: a multidisciplinary triangulation process. BMJ Open 2015;5:e006376.

16 Benson $\mathrm{H}$, Lucas $\mathrm{C}$, Kmet W, et al. Pharmacists in general practice: a focus on drug-related problems. Int J Clin Pharm 2018;40:566-72.

17 Chaio S, Toibaro J, Valicenti P, et al. [Adverse drug reactions and prescription errors: morbi-mortality]. Medicina 2013;73:111-8.

18 Lampert ML, Kraehenbuehl S, Hug BL. Drug-Related problems: evaluation of a classification system in the daily practice of a Swiss university hospital. Pharm World Sci 2008;30:768-76.

19 Taegtmeyer AB, Curkovic I, Corti N, et al. Drug-related problems and factors influencing acceptance of clinical pharmacologists alerts in a large cohort of neurology inpatients. Swiss Med Wkly 2012;142:w13615.

20 Hammar T, Lidström B, Petersson G, et al. Potential drug-related problems detected by electronic expert support system: physicians' views on clinical relevance. Int J Clin Pharm 2015;37:941-8.

21 Tora $\mathrm{H}$, Bo H, Bodil L, et al. Potential drug related problems detected by electronic expert support system in patients with multi-dose drug dispensing. Int J Clin Pharm 2014;36:943-52.

22 Leopoldino RD, Santos MT, Costa TX, et al. Drug related problems in the neonatal intensive care unit: incidence, characterization and clinical relevance. BMC Pediatr 2019;19:134

23 Abunahlah N, Elawaisi A, Velibeyoglu FM, et al. Drug related problems identified by clinical pharmacist at the internal medicine ward in turkey. Int J Clin Pharm 2018;40:360-7.

$24 \mathrm{Ma} \mathrm{SN}$, Zaman Huri H, Yahya F. Drug-Related problems in patients with rheumatoid arthritis. Ther Clin Risk Manag 2019;15:505-24.

25 Bedouch P, Allenet B, Grass A, et al. Drug-Related problems in medical wards with a computerized physician order entry system. $J$ Clin Pharm Ther 2009;34:187-95.

26 Blix HS, Viktil KK, Moger TA, et al. Characteristics of drug-related problems discussed by hospital pharmacists in multidisciplinary teams. Pharm World Sci 2006;28:152-8.

27 Roten I, Marty S, Beney J. Electronic screening of medical records to detect inpatients at risk of drug-related problems. Pharm World Sci 2010;32:103-7.

28 Semcharoen K, Supornpun S, Nathisuwan S, et al. Characteristic of drug-related problems and pharmacists' interventions in a stroke unit in Thailand. Int J Clin Pharm 2019;41:880-7.

29 Guignard B, Bonnabry P, Perrier A, et al. Drug-Related problems identification in general internal medicine: the impact and role of the clinical pharmacist and pharmacologist. Eur $\mathrm{J}$ Intern Med 2015;26:399-406.

30 Wong CY, Chaudhry SI, Desai MM, et al. Trends in comorbidity, disability, and polypharmacy in heart failure. Am J Med 2011;124:136-43.

31 Urbina O, Ferrández O, Grau S, et al. Design of a score to identify hospitalized patients at risk of drug-related problems. Pharmacoepidemiol Drug Saf 2014;23:923-32.

32 Blix HS, Viktil KK, Reikvam A, et al. The majority of hospitalised patients have drug-related problems: results from a prospective study in general hospitals. Eur J Clin Pharmacol 2004;60:651-8.

33 Frisse S, Röhrig G, Franklin J, et al. Prescription errors in geriatric patients can be avoided by means of a computerized physician order entry (CPOE). Z Gerontol Geriatr 2016;49:227-31.

34 Slight SP, Eguale T, Amato MG, et al. The vulnerabilities of computerized physician order entry systems: a qualitative study. $J$ Am Med Inform Assoc 2016;23:311-6.

35 Hellot-Guersing M, Jarre C, Molina C, et al. [Medication errors related to computerized physician order entry at the hospital: Record and analysis over a period of 4 years]. Ann Pharm Fr 2016;74:61-70.

36 Westerlund T, Gelin U, Pettersson E, et al. A retrospective analysis of drug-related problems documented in a national database. Int J Clin Pharm 2013;35:202-9.

37 Rhalimi M, Rauss A, Housieaux E. Drug-Related problems identified during geriatric medication review in the community pharmacy. Int $J$ Clin Pharm 2018;40:109-18.

38 De Bock L, Tommelein E, Baekelandt $\mathrm{H}$, et al. The introduction of a full medication review process in a local Hospital: successes and barriers of a pilot project in the geriatric ward. Pharmacy 2018;6:21.

39 Maes KA, Tremp RM, et al, GSASA Working group on clinical pharmacy. Demonstrating the clinical pharmacist's activity: validation of an intervention oriented classification system. Int J Clin Pharm 2015;37:1162-71.

40 Dryden L, Dewhurst NF. Integration of a clinical pharmacist into a Canadian, urban emergency department: a prospective observational study. Int J Pharm Pract 2019;27:175-9.

41 Foroughinia F, Tazarehie SR, Petramfar P. Detecting and managing drug-related problems in the neurology ward of a tertiary care teaching hospital in Iran: a clinical pharmacist's intervention. $J$ Res Pharm Pract 2016;5:285-9.

42 Choi KS, Lee E, Rhie SJ. Impact of pharmacists' interventions on physicians' decision of a knowledge-based renal dosage adjustment system. Int J Clin Pharm 2019;41:424-33.

43 Lenssen R, Heidenreich A, Schulz JB, et al. Analysis of drug-related problems in three departments of a German university hospital. Int $J$ Clin Pharm 2016;38:119-26.

44 Verdoorn S, Kwint HF, Hoogland P, et al. Drug-Related problems identified during medication review before and after the introduction of a clinical decision support system. J Clin Pharm Ther 2018;43:224-31.

45 Kim MG, Jeong CR, Kim HJ, et al. Network analysis of drug-related problems in hospitalized patients with hematologic malignancies. Support Care Cancer 2018;26:2737-42.

46 Viprey M, Jeannin R, Piriou V, et al. Prevalence of drug-related problems associated with direct oral anticoagulants in hospitalized patients: a multicenter, cross-sectional study. J Clin Pharm Ther 2017;42:58-63.

47 Basger BJ, Moles RJ, Chen TF. Application of drug-related problem (dRP) classification systems: a review of the literature. Eur $\mathrm{J}$ Clin Pharmacol 2014;70:799-815. 